Revista Iberoamericana. Vol. LXIV, Núms. 184-185, Julio-Diciembre 1998; 529-542

\title{
LA VIOLENCIA DEL GÉNERO Y LA NARRATIVA DEL EXCESO: NOTAS SOBRE MUJER Y RELATO EN DOS NOVELAS ARGENTINAS DE PRINCIPIOS DE SIGLO
}

POR

\author{
Sylvia Molloy \\ New York University
}

No hay disturbio patológico en sí. Lo anormal sólo se puede evaluar en términos de una relación.

Georges Canguilhem, Lo normal y lo patológico

\section{LA ESCENA DEL RELATO}

Durante un largo, brumoso, verlainiano otoño, un narrador visita regularmente a una mujer y, en cada visita - en cada sesión- le narra una historia. El ejercicio narrativo asegura la continuidad de la relación, mejor, el ejercicio narrativo constituye la relación. Poco o nada se sabe del narrador, menos de la mujer, aunque su autoridad es obvia. Dueña del espacio donde se desarrolla el ejercicio, yajardín melancólico a fines del verano, ya salón decadente al acercarse el invierno, es ella quien, “ávida de fábulas" (Borderland 19), marca el ritmo, exige $(45,72)$. El narrador, Sherazada transvestido, obedece: cuenta, se detiene cuando la mujer se lo indica (como las terapias, estas sesiones se interrumpen, no se terminan), y se despide, marchándose para volver, la vez siguiente, con un nuevo relato. La ceremonia narrativa es de y para la mujer, su propósito es colmar una nunca satisfecha necesidad, un "ansia enfermiza" (19) de historias cuyo objetivo, calculado, es el frisson del placer y del miedo. El narrador conoce bien estos gustos particulares de la mujer, "la sugestión del horror que es en usted una de esas predilecciones inexplicables" (106).

La mujer, solitaria, reclusa, permanece anónima. Físicamente, aparenta un ícono prerrafaelita: “Alta, fina, singularmente pálida, tenía las manos afiladas y expresivas y el aire pasmado de esos niños trágicos que pasan con ojos atónitos por los cartones de miss Kate Greenaway" (19), descripción que recurre a lo largo del texto como una suerte de mantra. Sorprendentemente (puesto que apenas habla) se la llama "la interlocutora", como si su silencio, su "postura tendida de esfinge" (20) fuese, en sí, acto de locución y parte del diálogo. Cuando habla, es para provocar el relato al comienzo; pero no habla nunca al final, es decir no reacciona: interrumpe. También se la llama "Ella", universalizándola genéricamente, como en ciertos poemas de Darío, y —en las escasas ocasiones en que el narrador hace una acotación que requiere la interpelacion directa- se la llama, con el respeto debido, "Señora". No se trata de una seducción amorosa sino del pago de un tributo al soberano. Una vez más este desnivel jerárquico recuerda al sultán y Sherazada, con una 
diferencia importante: la interrupción definitiva del relato lleva no a la muerte de quien cuenta sino a la muerte del receptor.

La escenificación del acto de narrar — como marco de relato y a la vez su anécdota misma- es fundamental en la literatura latinoamericana finisecular. Signada casi exclusivamente por lo masculino, es escena de homosociabilidad por excelencia: en la amena causerie del club, la charla de café, el encuentro en el atelier de pintor, la sobremesa - escenas a las cuales pueden añadirse el intercambio de opiniones clínicas en el gabinete diagnóstico o la redacción del prontuario en el departamento de policía- colaboran exclusivamente hombres, arman relatos acerca del aquello marginado, fascinante y amenazador, que es lo femenino. Por lo menos dos textos del modernismo se titulan De sobremesa, la novela de José Asunción Silva y un poema de Darío. La expresión es densa, con sus ricas connotaciones de exceso, de suplementaridad: la sobremesa es lo que está más allá de la satisfacción inmediata, lo que supera el límite de la incorporación necesaria y dilata la clausura, es el derroche, acaso el desorden, que supera y por ende cuestiona el límite de la convención.

Si elijo centrar mi comentario en Borderland (1907) y La eterna angustia (1908), novelas del argentino Atilio Chiáppori, es porque rompen precisamente con ese esquema homosocial, por lo menos en apariencia. ¿Qué ocurre, quiero preguntarme, cuando el relato pasa no de hombre a hombre sino de hombre a mujer? ¿Cuando no se da en el ámbito institucional o institucionalizado (el club, el gabinete, el café, el consultorio) sino en el margen? Además: ¿qué desplazamientos de sentido se operan a nivel del enunciado, qué nuevas formulaciones ideológicas favorecen el cambio? Más concretamente: ¿qué pasa con la representación de lo femenino, por lo menos compleja (cuando no misógina) en el discurso masculino cuando el objetivo de la transacción narrativa ya no es la complicidad entre hombres, cuando el destinatario de esa representación es una mujer? Las notas que siguen intentan, en parte, contestar a esas preguntas a la vez que reflexionar, de manera más general, sobre la ansiedad que suscitan ciertas representaciones de "lo femenino" en el fin de siglo hispanoamericano.

\section{UN RELATO DE FRONTERA}

Escritor de principios de siglo, colaborador de La Nación, más tarde crítico de arte de La Prensa, profesor de estética, organizador cultural, director del Museo Nacional de Bellas Artes, académico: si las glorias oficiales no eludieron a Atilio Chiáppori no bastaron para asegurarle la sobrevida. Hoy nadie lo recuerda particularmente ni se leen sus libros. Sin embargo, sus dos sorprendentes novelas, Borderland y La eterna angustia - como tantos otros textos modernistas llamados "secundarios" menos por sus cualidades estéticas que por su resistencia a la fácil clasificación, su caracter "no canonizable" — son material ideal para una lectura que, al revisar categorías estrechas y desarmar presupuestos simplistas, aspira a una revisión de las culturas hispanoamericanas del fin de siglo.

Borderland, la primera novela de Chiáppori, se presenta como una serie de relatos sueltos. ${ }^{1}$ Proporciona el marco narrativo la situación a la que me he referido, la visita ritual

${ }^{1}$ De hecho, estos relatos se publicaron por separado en periódicos antes de ser reunidos en libro. No he podido establecer secuencias dentro de un mismo periódico que permitiera considerarlos relatos 
de un narrador a una mujer a quien ofrece, cada vez, un nuevo relato. Los mismos personajes, principalmente masculinos, aseguran la unidad de la anécdota. Miembros de la clase alta argentina, "verdadero[s] y típico[s] representante[s] del arrogante argentino de buena raza" (como escribe Osvaldo Magnasco, sin ironía, de Ramos Mejía [Ramos Mejía A martillo 61]), están relacionados además, con una notable excepción, por uno de los vínculos de mayor eficacia aglutinante entre hombres de la clase dirigente: la común asistencia a un colegio para élites, en este caso el colegio del Salvador. ${ }^{2}$ El doble recorte un selecto grupo masculino solidario dentro de otro grupo ya selecto e igualmente solidario- es de tenerse en cuenta. Borderland es, entre otras cosas, una reflexión sobre lo que Josefina Ludmer ha llamado la "coalición cultural" de fines del diecinueve. Pero Borderland es también como señala Emilio Becher acatando las connotaciones del título, relato de frontera que explora los bordes, las tensiones, los desvíos de esa coalición.

En cada uno de los relatos, un compañero de colegio cumple el papel protagónico. En cada uno de ellos, ese protagonista victimiza sistemáticamente a una mujer y en varios casos la destruye. En todos, el personaje masculino responsable directa o indirectamente de esa violencia enloquece o muere. En "Un libro imposible", de atmósfera pesadamente gótica, Augusto Caro, novelista experimental, a fin de superar el esquematismo con que suele retratar a sus personajes femeninos, emprende un largo entrenamiento psíquico que le permite descubrir y cultivar otras vidas y luego proyectarlas en una mujer real, una "modelo" a quien logra hacer vivir las existencias virtuales que ha imaginado (63): "No puedes siquiera presentir la voluptuosidad de penetrar en un alma, asistir a sus más íntimas transmutaciones y regirla, envolverse en ella, desaparecer en ella y ser otro ..."(65). Augusto subyuga a Anna Maria al punto de hacerle vivir, espontáneamente, todas sus fantasías. Una noche, "un deseo incontenible" (69) lo lleva a pedirle que represente lo que pasaría si él la estrangulara: la mujer, sin que él la toque, muere por estrangulación. En "La corbata azul" otro condiscípulo, Máximo Lerma, obsesionado con la idea de ahorcar a Luisa, su mujer, con una corbata azul de ésta, ve en un tranvía un cuello de mujer que le recuerda a Luisa. Preguntándose “¿Por qué serán tan frágiles los cuellos femeninos?” (74) regresa a casa y, luego de asistir al lento, sensual desvestirse de su mujer que se apresta a hacer el amor, la estrangula. En "El pensamiento oculto" el pintor Saúl Berthenoi, enloquecido por celos infundados, arroja a su mujer al río. En "La mariposa" Roberto Esprelo, un escritor, se separa de su mujer para emprender la escritura de una novela. Pero cuando "luchaba por hacer inteligible una imagen rebelde" una "repulsiva" "aterciopelada mariposa negra" (109) se empeña en posarse sobre las cuartillas. Esprelo la caza y al arrojarla al fuego oye un grito humano y ve surgir el rostro de su mujer, "¡Ojos de locura que me miraban perdidamente, que miraban hasta dentro del cerebro, registrándolo! Después fue un beso frío, un beso que

por entrega, aunque la estructura misma de la novela juegue con esa forma. De hecho parecen haberse publicado en periódicos diversos, donde habrán creado extrañas expectativas. Así por ejemplo el primer capítulo, titulado "La interlocutora", donde se plantean por así decirlo las reglas de juego que habrá de seguir la novela, se publicó aislado en el primer número de Nosotros, agosto de 1907, revista que no volvió a publicar más capítulos de Borderland.

${ }^{2}$ Sobre la eficacia del colegio en la formación de esa conciencia de grupo, ver también Molloy, "Una escuela...". 
no terminaba nunca; después no sé...” (111). Amanece vampirizado, con labios exangües y marcas de mordedura.

"El daño", relato final de Borderland, si bien reitera la victimización de lo femenino, difiere de los anteriores. Por lo pronto, Chiáppori -médico fallido, que había cursado la carrera hasta el quinto año- introduce la mirada diagnóstica y el mundo de la clínica. El narrador cuenta a la interlocutora la historia de Irene Caro, la "tan pálida, tan frágil, amorosa y buena" (117) hermana del protagonista del primer relato, que sufre de hemofilia. Pablo Beraud, el médico que, con "complicado vendaje" (115), logra restañar una primera hemorragia ocasionada por un rasguño en el brazo, se enamora de ella y ella de él. Piensan casarse, pese a las inquietudes del novio, escindido entre el amor y la conciencia de que "como médico, tenía un deber ineludible que cumplir: un deber que exigía el sacrificio inmediato de su ensueño" (116). En efecto, nos dice el texto haciendo alarde de conocimientos médicos y de conciencia eugenésica, el Dr. Beraud lleva un "aforismo fatídico" grabado en la memoria: "Sin excepción, debe prohibirse el matrimonio a los hemofílicos" (116). Pese a ello, no se atreve a romper el compromiso y la fecha de la boda se ha fijado, como desafío, en el aniversario de la primera herida.

El "aforismo fatídico", con su tajante interdicción, no especifica el género de los enfermos. Sin embargo la hemofilia es enfermedad que toca, de manera diferente y específica, a hombres y mujeres. Afecta principalmente a los primeros; es transmitida por las segundas. La atribución directa de la enfermedad a una mujer es por lo tanto insólita. El fundamento del aforismo también merece examen: en una época tan obsesionada con la herencia como lo es el final del siglo diecinueve, el riesgo de comprometer la descendencia, de degenerarla, es un aviso para el enfermo hombre: que no se case, que no procree. En el texto de Chiáppori, donde la enfermedad ha cruzado la barrera del género, el riesgo que se teme es muy otro: "En el primer beso nupcial — piensa el médico- esa existencia preciosa podría extinguirse en un soplo, como una llama que se apaga" (117). En la mujer, el peligro no reside en la procreación sino en el acto sexual mismo, en una penetración violenta que ha de provocar, fatalmente, el desangramiento.

Con notable inventiva, este relato de Chiáppori complica más aun los desvíos genéricos y sexuales. Aparece un tercer personaje, Flora Nist, ex-amante de Pablo Beraud, una de las creaciones femeninas más notables (y menos notadas) de la literatura finisecular. Encarnación local de la "mujer nueva", atlética, independiente, culta y bisexual, concentra en su ambigua figura rasgos contradictorios. De ella también se nos dice que es gran lectora, "educada con todas las libertades masculinas" (125), que en la biblioteca de su padre científico ha leído sobre todo estudios de patología mental, que conoce la práctica del hipnotismo y la sugestión, y que se interesa por sobre todo en una muy criticada y censurada monografia de un tal doctor Biercold en la que se propone que el hipnotizador puede programar al hemofilico para que sangre en un momento determinado por el lugar que el hipnotizador elija y marque, durante la hipnosis, con un leve rasguño. Flora consigue que Irene acuda sola a su casa y la hipnotiza, dictándole su "aciago mandato muy de cerca, como si la estuviese besando" (130). El desenlace acaso se prevea. La noche de la boda Irene se desangra en el lecho nupcial y su marido, echándose la culpa, enloquece. ${ }^{3}$

${ }^{3}$ La obsesión con ver fluir la sangre de la mujer es sin duda parte del imaginario de la época y cruza varias culturas. Piénsese en las manos cercenadas de Hipólita en El triunfo de la muerte de 
Las implicaciones de este crimen erótico por desplazamiento son notables, la incitación al voyeurismo, patente: ¿por qué herida (previa o actual, visible o invisible) se desangra Irene y en qué momento? ¿Por desfloración, por hipnosis, o por la desfloración de la hipnosis? Este relato, que interrumpe las sesiones narrativas, cierra la novela: es el único que logra suscitar una reacción. Presa de una "extraña palidez" (131), la Señora por fin habla, formula esas mismas preguntas: “¿Fue por la antigua cicatriz que se desangró la pobre Irene?” A lo cual responde el narrador "No, Señora, ningún médico se atrevió a mencionar el sitio de la herida..." La desproporción entre las dos lecturas posibles - la más pedestre, que Irene se desangró al ser desflorada por Pablo, o la más llamativa, que Irene se desangró por una herida secreta, indecible, una des-floración previa practicada por Flora y reavivada por la hipnosis - favorece evidentemente la segunda. Así lo entiende la interlocutora, como una intrusión, aberrante y definitiva, que clausura para siempre la ceremonia narrativa: al igual que la osada y maligna lesbiana, el narrador ha traspasado límites: "Jamás volví a verla. Esa tarde cerráronse, también para mí, las puertas" (131).

\section{LA ENTIDAD DE ORIGEN}

No se cierra en cambio la inventiva de Chiáppori: un año más tarde publicaba otra novela, La eterna angustia, descrita en el prólogo como "historia cuya esencia está llena de horror" y "crónica de sensaciones más bien que de hechos" (137), declaraciones sin duda prometedoras para los lectores de Borderland quienes verían satisfecha una vez más, como la interlocutora, su "ansia enfermiza" de relatos. Aquí un narrador —el mismo de Borderland - cuenta las vicisitudes de Leticia Dardani, la antigua interlocutora anónima, vicisitudes "que hacen pensar en el estigma litúrgico del anatema" (137). Queda claro que a Leticia, vuelta ahora personaje y no meramente escucha, no le espera nada bueno.

Con habilidad, la nueva novela vuelve sobre Borderland y reinscribe esa historia o más bien esas historias- en un marco temporal a la vez más preciso y más amplio. La novela comienza con el rescate de un pasado anterior a Borderland, evoca la estrecha amistad que unía al narrador adolescente con la joven mujer mayor que él, el desencanto de éste cuando Leticia inesperadamente acepta casarse con otro, el inexplicable suicidio del marido de Leticia a las dos semanas de la boda, la reclusión de Leticia viuda, reclusión sólo interrumpida - y aquí empalma La eterna angustia con Borderland - por el narrador cuyas visitas tolera Leticia a condición de que acepte tratarla formalmente y no tutearla. El narrador recuerda la interrupción de esas visitas rituales después del último, traumático relato, y luego pasa a describir su posterior trato con Leticia. A la ceremonia narrativa sucede una relación epistolar: de nuevo remedando la novela por entregas, la segunda novela de Chiáppori acumula cartas como antes relatos, cartas intercambiadas entre el narrador y

D'Annunzio o en el poema “Le Mani” del mismo autor. Chiáppori era sin duda lector de D'Annunzio, como lo atestigua la referencia a La hija de Iorio (otro texto de violencia misógina y delectación morbosa) en Borderland (40). Para ejemplos concretos de desangramientos estetizados en otras literaturas hispanoamericanos, ver Rubén M. Campos, "Pecado de amor" (Zaïtzeff 79) y Bernardo Couto Castillo, "Blanco y rojo" (Couto Castillo 57). En el primero, el desangramiento coincide con la confesión que hace una mujer de sus pecados. En el segundo, el desangramiento es una manera de acceder a un interior vedado. En los dos se vacía a la mujer de su secreto "contenido". 
Leticia, cartas donde Leticia expresa (luego se entenderá por qué) su creciente angustia y miedo a la muerte. Culmina esta correspondencia en una última carta enviada por Leticia al narrador antes de suicidarse, carta que va acompañada de un legajo enviado por el doctor Biercold (el mismo médico cuya perversa lección de hipnosis había causado la muerte de Irene al final de la novela anterior) justo antes de, él también, suicidarse. Como se ve, la novela no elude el recurso fácil, antes bien lo solicita. La lectura de la última carta de Leticia y del legajo de Biercold proveen, como es de esperarse, la clave de las muertes y, por fin, del misterio de la interlocutora.

El "extraño e incoherente legajo", compuesto de papeles sueltos escritos con "pulso alterado" (202), que el doctor Biercold envía a Leticia antes de morir y que determina a su vez el suicido de ésta, es un documento híbrido que combina varios géneros: carta de suicida, confesión de un crimen, autobiografía, denuncia social, y, principalmente, descripción de un experimento quirúrgico. Reproduce in nuce la estructura de relatos en serie cara a Chiáppori en tanto se presenta como un conjunto de páginas sueltas, de fragmentos narrativos en primera persona a los que el narrador, vuelto compilador, provee ilación, llevando a cabo "todo un minucioso trabajo de reconstrucción" (202). El documento de Biercold, a semejanza de los relatos anteriores de Borderland, narra una vez más la violencia de un hombre contra una mujer que lo rechaza y, coincidentemente, la violencia de un individuo contra una sociedad que no lo admite. Biercold, hijo de inmigrantes que no cabe del todo dentro del proyecto nacional, portador de un nombre extranjero, menos hijo de la patria que "hijastro" (203), es el profesional self-made que se destaca por su ambición y esfuerzo, superando "aquel apellido de "brasserie"" (204), y "mi traje color aceituna" (203). ${ }^{4}$ Pero su "lucha sorda y tremenda hasta llegar al tipo de profesional correcto y de buen tono" (203) de nada sirve para conquistar a Leticia, la mujer que ama y que no retribuye su amor. Su venganza, como la de Flora Nist, es médica; Biercold, "el mejor especialista para mujeres" (140), es llamado a operar a Leticia de un quiste dermoide en el vientre:

Advertí a sus padres y a los médicos de consulta que para no lacerar aquel cuerpo joven
y blanco, iba a tentar la oblación del tumor, sin abrir el vientre, por otra vía ... Eso lo
supieron mi practicante - un muchacho enfermizo que murió tuberculoso,
afortunadamente- y el encargado de la anestesia. Y al parecer, todo se hizo así. ¡Lo que
nadie supo, lo que nadie sabe, y ahora yo lo digo aquí con todas las palabras, es que no sólo
extirpé el tumor, sino también todos los órganos! ¡En mi vida me salió tan bien una
histerectomía completa! (208).

La desexué en sus raíces, en su entidad de origen. En eso nada más. El que viniera después, el indigno [...] tendría lo único que deseaba: el cuerpo sin un rasguño, pero frío, ¡frío y

\footnotetext{
${ }^{4}$ La burla de la indumentaria del extranjero, o hijo de extranjero, es frecuente. Un buen ejemplo es el caso de Ingenieros de cuyos trajes se burlan varios contemporáneos. Gálvez habla de "una espantable y descomunal levita gris" y observa que "el portador de semejantes horrores se creía elegantísimo y los ostentaba por todas partes con desparpajo sonriente" (Molloy, "Diagnósticos" 183). Lo mismo ocurre con el apellido. No falta quien siga llamando a Ingenieros "Ingegnieros", aun después de la modificación del apellido, para recalcar el origen italiano. Cabe especular que el propio Chiáppori acaso haya padecido burlas similares. Chiappa en italiano significa nalga.
} 
estéril para siempre jamás! Aquel cuerpo quedó blanco e intacto como al nacer. Pero la palpitación de vida, la posibilidad de las sensaciones, [...] lo eterno, lo mío, me lo llevé yo solo, silenciosamente... (209).

La lectura del legajo determina el suicidio de Leticia y el final de La eterna angustia. Póstumamente, el narrador ofrece a Leticia su último homenaje, su último relato: "Después, como estaba seguro de que nadie lo leería, por único epitafio le hice grabar este verso de Samain: Dors sans comprendre même un peu mon sacrifice" (210).

\section{EL DESAFUERO DE LO FEMENINO}

Hasta ahí, las novelas de Chiáppori. El mero resumen de sus peripecias -el mero intento de resumir sus peripecias - revela la naturaleza desaforada de estos relatos y lo que a primera vista podría juzgarse su facilidad temática. Éstas no debilitan, sin embargo, su riqueza ideológica, antes bien la refuerzan. No se trata de relatos alusivos o irónicos sino de relatos que practican la sobredeterminación a cada paso y cuya estrategia, aun cuando recurran al truco del "secreto", es por fin el excesivo decir. Como otros textos olvidados del modernismo, los relatos de Chiáppori, al igual que el melodrama analizado por Peter Brooks, "deben su existencia misma a la posibilidad, y necesidad, de decirlo todo" (Brooks 42). Borderland y Laeterna angustia (los títulos mismos lo dicen) recurren a la exageración, al efecto grand guignol. Representan con lujo de detalle, en una suerte de histriónico acting out ideológico, lo que el "buen" modernismo reprime: en particular construcciones de lo femenino y de lo sexual llevadas a un límite donde rozan, de hecho, la parodia y dejan percibir los encontrados impulsos que las animan. En textos como Borderland y La eterna angustia se revelan, mejor que en los relatos que la crítica ha canonizado, las tensiones de las construcciones de género, sus aspectos más problemáticos, sus intersecciones con otros discursos (médico, legal, cívico, político), sus puntos de fricción ideológica que desbordan, de hecho, en un campo cultural infinitamente más rico que el que suele reconocérsele a la literatura de fin de siglo. El hecho de que Chiáppori haya dedicado estas complejas figuraciones de lo femenino "A mi madre, religiosamente" no deja de añadir espesor a estos textos.

De las figuras que ilustran la compleja figuración de lo femenino en Chiáppori, sin duda Flora Nist es la más llamativa. Encarnación local de la "mujer nueva", es hija de un científico inglés y de una criolla. ${ }^{5}$ Atlética, independiente, culta - es universitaria, ex-

\footnotetext{
${ }^{5}$ Como ejemplo de ansiedad ante la "mujer nueva" en Hispanoamérica, cito de Darío: "Lo que no es aceptable son [...] la snob, la decadente, la wagnerista, la partidaria del amor libre, la Eva nueva, la doctora escandinava ibseniana y la estudiante rusa que tira balazos" ("A propósito de Mme. de Noailles" 305). El artículo, entra otras cosas, alaba a aquellas intelectuales francesas como Mme. de Stael y Mme. de Sévigné quienes, además de escritoras, fueron "muy plausibles mujeres de su casa" (305). Para un comentario general sobre el temor ante la "mujer nueva" en Francia, ver Silverman. La relación escandalosa y amenazadora de la "mujer nueva" con la nueva tecnología, observada por Silverman, es evidente en la descripción del automóvil que conduce Flora Nist: "En eso sonó de nuevo y muy cerca aquella bocina que gemía como una boca humana, y densa nube de polvo se levantó en el recodo de la alameda" (129).
} 
alumna de Smith College y libre y bisexual en sus amores - concentra en su figura rasgos divergentes. Por un lado es la intelectual asexuada, viste "con la elegancia rectilínea de las institutrices, habitual en las americanas del norte", con un "waterproof color ceniza que, desde el seno algo bajo, caía sin modelar un contorno hasta los finos tobillos" (119). Pero al continuar la descripción, en una suerte de strip-tease ideológico, el texto desecha significantes para revestir otros, en representación claramente conflictiva, como si Chiáppori lidiara con diversas y contradictorias figuraciones de lo femenino al mismo tiempo. Así, esta "institutriz" informe y neutra, al desprenderse del impermeable "lo mismo que si se desnudase" (119), se sexualiza a ultranza. La cabellera cobra un "peso excesivo", las caderas se liberan, los pechos se turgen, los muslos se comban, la figura cobra dimensiones mitológicas:

[S]u cuerpo adquiría ese contorno ofídico de la Venus Florentina. [...] Completaban ese aspecto extraño, las manos bárbaramente enjoyadas y su tez blanca, con esa blancura icteroide de las pelirrojas, dorada de antiguas manchas cicatriciales producidas por la explosión de una retorta en la que destilara el ámbar de sus perfumes raros. Bajo el amplio bucle frontal rojocobrizo, resaltaban sus grandes ojos verdes que, como las cimófanas, tornasoleaban la glauca pureza del berilo con los tonos sanguíneos del rubí (120).

La construcción va de la negación de la feminidad convencional a una hiperfeminidad casi monstruosa: se pretende aunar, en un mismo sujeto, a la intelectual anglosajona desfeminizada con la universal mujer fatal hechicera, en lo que resulta a las claras una figuración inestable, compuesta de imágenes hasta cierto punto excluyentes, en todo caso difícilmente reconciliables. Propongo que la crisis de representación que ofrece este retrato doble no es casual, que lo que el texto procura plantear, sin del todo saber cómo hacerlo, es una disidencia sexual carente de imagen - la lesbiana - que el texto no nombra pero construye mediante alusiones y que claramente no sabe dónde ubicar. Por ejemplo, al saludar a Irene, se nos dice que Flora la besa "muy cerca del cuello" (119): beso inadecuado, distinto, que sin duda remite a una tradición vampírica de indudables connotaciones homoeróticas. ${ }^{6}$

También se nos dice que la camarera Peggie, "morocha y musculosa", de mirada dura, "gruesos lentes", "rostro hombruno", y "poblado bozo" (124) cuida a Flora desde la muerte de su madre, y la acompaña "en todas sus correrías" (119). Desplazada excesiva y caricaturalmente sobre la marginalidad del subalterno, por añadidura extranjero (Peggie es sin duda anglosajona, posiblemente americana, y ha reemplazado a la "buena" madre criolla), la homosexualidad de Flora no por ello queda menos "dicha". Si la lesbiana no existe aún como categoría social y apenas existe como categoría médica, ${ }^{7}$ sin duda existe como entidad fluida, a la espera del nombre, y así, por su indeterminación misma, resulta tanto más amenazadora, tanto más pasible de encarnar múltiples desvíos, tanto más difícil

\footnotetext{
${ }^{6}$ Para un buen comentario de la identificación de la lesbiana con el vampiro, ver Case.

${ }^{7}$ Los estudios psicopatológicos de la época (Ingenieros, Veyga, Lugones) se refieren sobre todo a homosexualidad o "inversión" masculina. (Ver Salessi). Hay aislados trabajos sobre "uranismo" femenino, como el de Víctor Mercante.
} 
de hacer visible sin recurrir a la exageración, la parodia, la teratologización que permiten, a un tiempo, exhibirla y enjuiciarla. ${ }^{8}$

"Ambigua en su perversidad de libertinaje extenuado y alquimia clandestina": tal describe Emilio Becher a Flora Nist (16). De hecho, hay algo "clandestino" en todas las mujeres de Chiáppori, notablemente en las otras dos que cumplen papeles centrales en sus novelas, Irene Caro, "la más pura y noble de las mujeres imaginadas por el escritor" (Becher 11) y la enigmática interlocutora Leticia Dardani. Irene, dechado de virtudes, esconde una enfermedad incontrolable y vergonzosa; Leticia, la belleza prerrafaelita, un abominable quiste en el vientre. En ambos casos se trata de males secretos, "suelen pasar desapercibidos [...] Luego no duelen, ni se contagian" (184). Son anomalías que no se ven, que sólo la mujer y el agente de su destrucción conocen. En los dos casos la penetración médica - ya del doctor Biercold, ya de Flora Nist, su discípula - revela la verdad de la enfermedad vaciando al sujeto. El locus de la enfermedad es la sexualidad misma: la sangre uterina de Irene, los órganos de Leticia ("lo mío, me lo llevé yo solo") son los tristes trofeos de esta contienda. En los dos casos, por fin, la intervención médica ocurre en vísperas de un casamiento, obstaculizando la heteronormatividad que ese casamiento sancionaría: la verdad del secreto femenino se hace patente a los maridos y destruye la viabilidad del matrimonio. Notablemente, a medida que la psiquiatría europea, a partir de Charcot, ${ }^{9}$ se empeña en disociar los males "femeninos" y en particular la histeria del origen genital que se les solía atribuir, el imaginario social en cambio refuerza ese vínculo. Irene y Leticia están enfermas, más que de hemofilia y de quistes, de su propia sexualidad: de ahí la necesidad de extirparla. En otras palabras: a medida que las representaciones de lo femenino se vuelven más complejas y menos estables, aumentan los esfuerzos por genitalizar el género, domiciliarlo "en su entidad de origen" (209), como aumenta, proporcionalmente, la necesidad de controlar las manifestaciones de ese género, cuando no castigarlas.

\section{ESPECIALISTAS EN MUJERES}

La figuración del médico como protagonista finisecular, ya como personaje de ficción, ya como actor influyente en la escena sociopolítica; la patologización del ejercicio literario; la concepción de la medicina como práctica cultural y, significativamente, el recurso contínuo de la medicina a prácticas culturales estéticas (literatura, teatro, artes plásticas), "contaminando" la misma especificación científica que por otra parte busca establecer, son aspectos primordiales de las culturas finiseculares y cobran especial relieve en Hispanoamérica. ${ }^{10} \mathrm{La}$ importancia de la medicina en las novelas de Chiáppori es evidente.

\footnotetext{
${ }^{8}$ Una vez que la ha vuelto visible, parecería que a Chiáppori le cuesta deshacerse de Flora Nist. Un relato muy posterior, "El último vals" (Prosa 159-175), retorna al personaje y resume toda su historia. En ese nuevo relato Flora se casa por conveniencia y en vísperas de la boda "su camarera y confidente, Peggie murió de modo extraño" (167). Por fin (y como si ya no supiera cómo desembarazarse de ella), Chiáppori la hace desaparecer de manera adecuadamente hiperbólica: en una fiesta Flora conquista a un joven apuesto y, enlazados los dos en un frenético vals, ante la mirada reprobatoria de la concurrencia, se desploman al vacío desde una terraza.

${ }^{9}$ Para una evolución de la historia de la enfermedad y de sus causas, ver Gilman et al. Hysteria Beyond Freud, en especial los trabajos de Roy Porter y Elaine Showalter.

${ }^{10}$ Ver Molloy, "Diagnósticos".
} 
Ya por interpósita persona en la figura de Flora Nist al final de Borderland, ya directamente en la intervención de Biercold al final de La eterna angustia, la práctica médica, si se quiere aberrante pero no por ello desprovista de pretensiones "científicas", clausura el texto a la vez que destruye, en ambos casos, a la mujer. En este sentido, es particularmente interesante que el médico en estas novelas no sea el neurólogo o psiquiatra habitual en relatos de este tipo sino el ginecólogo, "especialista para mujeres" (140). Sólo después de la ginecología —podría decirse que llevado por la ginecología - Biercold se hace psiquiatra.

El hombre (o la mujer) de ciencia maligno, posiblemente diabólico, también es lugar común de buena parte de la literatura decimonónica. Chiáppori aprovecha el estereotipo y carga las tintas tanto con el doctor Biercold como con Flora, su aprendiz. De Biercold, sabemos que después de operar a Leticia deja la ginecología para dedicarse a una práctica perversa de la psiquiatría, que se vuelve bohemio, cae en el alcoholismo y en momentos de melodramático delirium tremens se hace pasar por el diablo: "Soy Roberto de Grandmont, poeta, y tengo mil años" (195). De Flora, sabemos que practica "caprichosas alquimias de boudoir" (124) y tiene fama de hechicera, fama justificada por su aspecto exótico y bárbaro. De ella escribe Chiáppori en un relato ulterior, donde reaparece como personaje, que "era de esas mujeres de las que uno se aparta porque el miedo que infunden sobrepasa la ansiedad del deseo"(165). Pero más allá de estas concesiones al cliché amenazador, Chiáppori adecua el estereotipo a contextos locales, se hace eco de los pánicos y desconfianzas de una época, construye a sus "científicos" como peligros reales. Predomina, en este trabajo paranoico, la idea de mezcla sospechosa: mezcla de nacionalidades y de clases sociales(Flora anglocriolla, de padre extranjero y madre cubana, Biercold hijo de inmigrantes pobres); mezcla de sexualidades (Flora lesbiana o bisexual, Biercold de impulsos igualmente ambiguos), ${ }^{11}$ mezcla de actividades (Biercold ginecólogo, psiquiatra, erudito, bohemio, poeta; Flora amazona, alquimista, estudiosa, femme fatale), son los dos, por sobre todo, sujetos inestables, no confiables aunque - a diferencia de la típica figura de inmigrante en la ficción de la época, pongamos por caso el Genaro de En la sangre de Cambaceres- no carecen de cierta grandeza. No son ridículos: pasan socialmente (como no pasaba Genaro ni tampoco el doctor Biercold cuando aspiraba a ser "discreto"12) pero pasan como raros: sus desvíos, su extravagancia misma ratifica la norma social que, necesaria y complejamente, los tolera.

\footnotetext{
"Se describe a Biercold emborrachándose con su joven ayudante, "un muchacho lampiño y ambiguo", y terminando la noche de bebida "con un enternecimiento lloricón y de tuteos" (183). Cabe recordar que la "inversión" sexual es, para muchos críticos sociales de la época, metáfora del desorden y la inadaptabilidad (y consiguiente razón de rechazo) de ciertos inmigrantes. Así Ramos Mejía describe al italiano guarango como "un invertido del arte [que] se parece a los invertidos del instinto sexual que revelan su potencia dudosa por una manifestación atrabiliaria de los apetitos" (Multitudes 257). También describe los hábitos de los prestamistas judíos como "las mieles nauseabundas de sus procedimientos de seducción [que] acaban de caracterizar su verdadera índole moral enrolándolos en la larga protervia de los invertidos" (Simuladores 167).

${ }^{12}$ Esto bien lo sabe Biercold, quien tiene conciencia de haber perdido a Leticia por discreción: "Ah! ¡si hubiera sido feo, feo con ganas, o a lo menos hubiese tenido el gusto de lo excéntrico - chalecos llamativos, sombreros enormes-, o simplemente, mal gusto! En cambio, para vestirme tenía buen gusto, un correcto, discreto buen gusto ... Concíbese que tanta regularidad, corrección y timidez me disminuyera.." (205). Es imposible no ver en esta declaración una alusión a las excentricidades de vestuario de José Ingenieros. Ver Molloy, "Diagnósticos".
} 
Si los actos de destrucción en estos textos se deben a un gesto médico, es importante notar que ese gesto está estrechamente relacionado con la lectura y la escritura; que los dos agentes de muerte, Flora y Biercold, son ellos mismos lectores y escritores y sus respectivas intervenciones son, a su manera, escrituras. Así, la muerte de Irene Caro se inspira en la lectura que hace Flora Nist de un escrito del doctor Biercold: el texto proporciona la receta del crimen. Así, la muerte de Leticia resulta de la lectura del "documento" del doctor Biercold: el texto proporciona la motivación al suicidio. Además, ambas intervenciones exigen una marca, la inscripción secreta sobre un cuerpo. En el caso de Irene, se autosugestiona a la mujer para hacerla sangrar, pero se necesita una marca física previa, un rasguño, para que brote la sangre. En el caso de Leticia, se efectúa una histerectomía manual sin marca exterior, es decir dejando la página en blanco - "para no lacerar aquel cuerpo joven y blanco" (208); "Aquel cuerpo quedó blanco e intacto como al nacer" (209) — ${ }^{13}$ pero tocando el interior de tal manera que la intervención se vuelve descifrable (el marido de Leticia lee la marca secreta y se suicida).

\section{ENGENDRO/EN GÉNERO}

Vuelvo sobre la disparatada operación del doctor Biercold — la excisión de un quiste dermoide "por otra vía" que culmina en una histerectomía manual- para detenerme en la naturaleza misma de la afección, tanto por su morfología como por sus proyecciones simbólicas. Según definición de diccionario médico, quiste dermoide es un "tumor formado de tejido embrionario, consistente en membranas fibrosas revestidas de epitelio y una cavidad que contiene materia grasa, pelo, dientes, fragmentos de hueso y cartílago" (Mosby). El texto de Chiáppori, si bien coincide con ciertos elementos de esta definición, le añade (le inventa) otros detalles:

[S]on especies de formaciones que contienen todos los tejidos, todos, del organismo vivo, al punto que, de haberse desarrollado, podrían constituir un nuevo ser. [...] [S]e atestigua la presencia en tales quistes de cartílagos, huesos, músculos, glándulas, uñas, cabellos y hasta órganos de los sentidos y materia encefálica. Es decir: la existencia en un cuerpo de otro cuerpo detenido en su perfección (184-5).

La idea del embarazo monstruoso y de una partenogénesis fallida (el "ser" en potencia es una malformación, un conjunto aberrante pero sensible, con "sentidos y materia encefálica") complica desde luego la descripción científica cruzándola con discursos de lo fantástico y lo gótico. No me interesa detenerme tanto en esos cruces como en la presentación de la afección misma, en su materialidad repulsiva. Lucrecia no padece una enfermedad finisecular prestigiosa - digamos lo que Bram Dijkstra llama el "consumptive sublime", la sublimidad tísica (29) o la misma, estetizada hemofilia de Irene - sino una deformidad explícita y resueltamente antiestética. Como en tantos otros textos finiseculares, podría decirse que en La eterna agustia el misterio gótico ha sido reemplazado por el

\footnotetext{
${ }^{13}$ El mantener el cuerpo femenino "intacto", sin marca exterior de destrucción, es idea cara a los lectores de Chiáppori. Así Emilio Becher, en su prólogo a Borderland, aprecia que en el caso de Irene Caro, "la muerte la fulmina sin deformarla" (11).
} 
voyeurismo clínico, el frisson metafísico por la curiosidad patológica. No fascina tanto la idea de un cuerpo dentro de otro como que ese cuerpo, en el sentido físico del término, sea una masa precisa, un conjunto repugnante de pelos, uñas, huesos, y que ese conjunto repugnante esté dentro del bello cuerpo de una mujer. Acaso mejor: que ese conjunto repugante sea, de algún modo, la mujer. Por manipulación del médico, Leticia sin saberlo alumbra un doble secreto: el de su enfermedad (el quiste dermoide) y el de su sexualidad: "no sólo extirpé el tumor, sino también todos los órganos! [...] La desexué en sus raíces, en su entidad de origen" (208-9).

\section{CONTAR, CORTAR, CONTROLAR}

Las novelas de Chiáppori pueden leerse - y de hecho se han leído- como otras tantas novelas sensacionalistas del fin de siglo que buscan el escalofrío barato. Si bien tal lectura no es impertinente (ni tampoco frívola), no toma en cuenta debidamente el cruce provocador que propone Chiáppori entre intervención médica e intervención narrativa en lo tocante a lo femenino. Regreso a la escena del relato para detenerme, una vez más sobre su estructura. En Borderland cada una de las narraciones independientes que el narrador trae a su interlocutora reproduce la situación de enunciación del marco, es decir, en casi todos hay un cuento que se cuenta, o una carta que se escribe a otro, como si a través de esa reiteración se buscara recalcar el carácter eminentemente narrable, repetible, de estas anécdotas que evidencian el desasosiego, la violencia del género. Esta reiteración no es infrecuente en el relato modernista, donde se privilegian las situaciones de transmisión, de relevo narrativo: el relato sobre la mujer, previamente contado al narrador por otro, pasa de éste a sus escuchas en un gesto desinteresado, el puro, fluido placer de narrar - de lucirse - entre y para hombres. En cambio en Borderland esa fluidez se corta. Desde el comienzo sabemos que la serie de relatos ha de interrumpirse: "la tarde en que presintió que estaba a punto de adivinar su secreto, cerráronse para mí también las puertas" (19). Sin duda truco narrativo para crear suspenso, la declaración es algo más. Confirma, desde un principio, el fracaso de la transacción cuando se cambian las reglas del juego: no es la escena de relato habitual del modernismo, aquí pasa otra cosa.

En la escena que plantea Chiáppori, el relato no pasa a la mujer para que ella, a su vez, eventualmente lo narre, sino que se detiene, se aposenta en ella, la marca. El desnivel jerárquico al que apunté al principio - la mujer es figura de autoridad, es dueña del espacio, ritma la ceremonia narrativa- se invierte: la interlocutora no asumirá nunca la pasajera autoría de la narración, no asegurará nunca la transmisión del relato. ¿A quién se lo contaría? La transacción narrativa entre hombre y mujer no se basa en la complicidad y en la potencial reversibilidad de roles sino en un enfrentamiento, un doble desafío: el narrador cuenta para penetrar, a través de los sucesivos relatos, el secreto que esconde la mujer, para provocar su respuesta; la mujer calla para mantener intacto el secreto, para no reaccionar ante relatos que aluden a ese secreto muy de cerca, tanto que el narrador llega al borde mismo del descubrimiento. La impavidez y el silencio de la interlocutora constituyen, en efecto, su goce narrativo, su placer de no contar. No en vano, "con vaga sonrisa ocultadora", suele citar a Samain: "Elle vivait pour la volupté de se taire" (106-7). 
Del narrador poco se sabía en Borderland salvo que era proveedor de relatos. Aparentemente cumplía funciones de subordinado en todos los respectos menos uno: era dueño de la narración. La segunda novela, al aclarar los lazos que lo unen a la interlocutora desde mucho antes, permiten ver la relación de modo muy distinto, ya no sólo como transacción narrativa sino como historia de amor frustrado. Porque el lector de La eterna angustia se entera de que el narrador es diez años menor que Leticia, que carece del prestigio del hombre con quien Leticia eventualmente se casa, que ocupa el lugar del suspirante desplazado y disminuido: es confidente, nunca amante. En suma, y salvadas las distancias sociales, ocupa un lugar casi tan deslucido como el del resentido doctor Biercold. Tanto más notable, entonces, es el hecho de que sea ese mismo narrador quien recomiende a Leticia, en un gesto de cuestionable inocencia, que se haga operar de su "quiste dermoide" por el doctor Biercold porque "era el mejor especialista para mujeres [...]" (140).

Esta información obliga, por cierto, a una relectura de las dos novelas, y a una interpretación más compleja de la ceremonia narrativa que las estructura. Piénsese que, en el momento en que comienzan las visitas rituales del narrador a la interlocutora, esta ya ha sido operada, es decir desexuada, "en sus raíces, en su entidad de origen" (209) por el "especialista para mujeres" recomendado por el propio narrador. Piénsese también, que ni el narrador ni la interlocutora saben a qué extremos ha llegado esa intervención; desconocen la extensión de ese "vacío" secreto que ambos sin embargo intuyen en el "ansia enfermiza", la "avidez" de la mujer por llenarse de fábulas, su necesidad de defender lo indecible. Piénsese por fin en el cuidado que Chiáppori ha puesto en construir esta perversa escena de relato en que un narrador, incapaz de conquistar a una mujer pero no incapaz de narrarla, sistemáticamente colma de relatos a la que indirectamente ha contribuido a vaciar de su (repugnante) feminidad, de relatos que reiteran, con variantes, la violencia misma de que ha sido víctima. El gesto de reconocimiento del narrador, al terminar de leer la confesión de Biercold, es significativo: "al pasar frente al espejo, tuve miedo de mi fisonomía" (210). Las novelas de Chiáppori dejan en claro que el relato del género, tanto en el nivel del narrador como en el del autor, no difiere tanto de la intervención quirúrgica: que es otro gesto ansioso, violento, de "especialista para mujeres" empeñado en controlar el desorden, en reclamar, como Biercold, "lo suyo".

\section{Obras CitADAS}

Brooks, Peter. The Melodramatic Imagination: Balzac, Henry James, Melodrama, and the Mode of Excess. 1976. Nueva York: Columbia University Press, 1984.

Canguilhem, Georges. The Normal and the Pathological. Introducción de Michel Foucault. Nueva York: Zone Books, 1989.

Becher, Emilio. "Prólogo" a Chiáppori, Atilio. Borderland. La eterna angustia. Buenos Aires: Editorial Kraft, 1954.

Case, Sue-Ellen. "Tracking the Vampire." Differences 3 (Summer 1991): 1-20.

Chiáppori, Atilio. Borderland. La eterna angustia. 1907-1908. Prólogo de Emilio Becher. Buenos Aires: Editorial Kraft, 1954.

Prosa narrativa. Noticia preliminar de Sergio Chiáppori. Buenos Aires: Academia Argentina de Letras, 1986. 
Couto Castillo, Bernardo. Asfódelos. 1897. La Matraca, 1984.

Darío, Rubén. “A propósito de Mme. de Noailles”. Obras completas I. Madrid: Afrodisio Aguado, 1950-55. 300-308.

Gilman, Sander, et al, comp. Hysteria Beyond Freud. Berkeley-Los Angeles-Londres: University of California Press, 1993.

Dijkstra, Bram. Idols of Perversity: Fantasies of Feminist Evil in Fin-de-Siècle Culture. Nueva York y Oxford: Oxford University Press, 1986.

Ludmer, Josefina. "Introducción" a Miguel Cané. Juvenilia y otras páginas argentinas. Buenos Aires: Austral, 1993.

Mercante, Víctor. "Fetiquismo y uranismo femenino en los internados educativos". Archivos de Psiquiatria, Criminología y Ciencias Afines (1905): 22-30.

Molloy, Sylvia. "Una escuela de vida: Juvenilia de Miguel Cané". Acto de presencia: La escritura autobiográfica en Hispanoamérica. México: Fondo de Cultura Económica y El Colegio de México, 1997. 133-145.

"Diagnósticos del fin de siglo". Cultura y tercer mundo, vol. 2. Cambios de identidades y ciudadanias. Beatriz González, ed. Caracas: Ediciones Nueva Sociedad, 1996. 171-200.

Mosby's Medical, Nursing, and Allied Health Dictionary. 5th edition. Saint Louis, Baltimore, New York, etc.: Mosby, 1998.

Ramos Mejía, José María. A martillo limpio. Estampas y siluetas repujadas. Introducción de Osvaldo Magnasco. Buenos Aires: Compañía Impresora Argentina, 1959.

Las multitudes argentinas. 1899. Buenos Aires: Talleres Gráficos Argentinos L.J. Rosso, 1934.

Los simuladores del talento. 1904. Buenos Aires: Editorial Tor, 1955.

Salessi, Jorge. Médicos, maleantes y maricas. Rosario: Beatriz Viterbo, 1995.

Silverman, Deborah. "Amazone, Femme Nouvelle, and the Threat to the Bourgeois Family". Art Nouveau in Fin-de-Siècle France: Politics, Psychology, and Style. Berkeley y Los Angeles: University of California Press, 1989.

Zaïtzeff, Serge. Rubén M. Campos. Obra literaria. Guanajuato: Ediciones del Gobierno del Estado de Guanajuato, 1983. 